\title{
Selective Inhibition of Stimulation Responses of Neutrophils by Membrane Modulators
}

\author{
Eisuke Sato, Yoshiki Takehara ${ }^{1}$, Junzo Sasaki', Tsuyoshi Matsuno ${ }^{2}$, \\ and Kozo Utsumi \\ Department of Medical Biology, Kochi Medical School, Kochi 781-51, Japan, \\ ${ }^{1}$ Department of Anatomy and ${ }^{2}$ Department of Surgery, Okayama University \\ Medical School, Okayama 700, Japan
}

\begin{abstract}
Polymorphonuclear leukocytes undergo a series of morphological and biochemical changes in response to various chemical stimuli. Transmembrane potential change is an early event that follows stimulation and membrane depolarization may act as a trigger for superoxide generation. To determine if there is a correlation between membrane depolarization and superoxide generation, we investigated the effects of different membrane modulators on stimulus-dependent depolarization. The membrane modulators mepacrine, chlorpromazine and cepharanthine inhibited the superoxide generation produced by chemotactic peptide, FMLP, and/or digitonin in neutrophils. Inhibitory profiles of the activation parameters, however, demonstrate that membrane depolarization is not associated with superoxide generation: FMLP-induced depolarization was inhibited by the modulators tested and was accompanied by the suppression of superoxide generation, but the depolarization produced by digitonin was stimulated somewhat by these drugs. Our results indicate that receptor-mediated membrane depolarization is not a necessary event for the activation of superoxide generation by digitonin.
\end{abstract}

When stimulated with both soluble and particulate stimuli, polymorphonuclear leukocytes (PMN) display a dramatic series of biochemical and morphological changes $(1,20)$. These changes are induced by modifying the membrane surfaces; there is no accompanying entrance of the chemical stimuli. But the exact mechanism by which surface modulation activates these leukocyte functions is poorly understood.

Previous investigators have suggested that PMN has characteristics very similar to those of excitable cells such as muscle and nerve cells. Therefore, a change in transmembrane potential may play an important part in phagocytotic processes, and it has been suggested to be the initial event in metabolic activation $(4,7,8,19,25)$. A high degree of correlation of stimulus-dependent changes in the transmembrane potential to the production of superoxide generation also has been demonstrated $(6,10,19,25)$. Thus membrane depolarization has been suggested to trigger the

Abbreviations used: FMLP, formylmethyonyl-leucyl-phenylalanine; PMN, polymorphonuclear leukocytes; KRP, Krebs-Ringer-Phosphate; Con A, concanavalin A; diS-C 3 -(5), 3,3'-dipropylthiadicarbocyanine iodide; CPZ, chlorpromazine. 
activation of respiratory bursts (3). The actual role of membrane potential and the causal sequence between it and superoxide generation, however, has still to be determined.

To better understand the process of superoxide generation by membrane perturbants, we studied the effect of various membrane modulators on membrane potential change and superoxide generation of PMN induced by chemotactic peptides and digitonin. We here report that superoxide generation of PMN is a reaction independent of membrane potential change and that the sensitivity of membrane potential change to membrane modulators in PMNs differs for each stimuli.

\section{MATERIALS AND METHODS}

Chemicals. All reagents were purchased from Sigma Chem. Co. (St. Louis. Mo. USA) except where indicated. Cyanine dye, 3,3'-dipropyl-2,2'-thiodicarbocyoanine iodide [diS$\mathrm{C}_{3}-(5)$ ], was donated by Kankoshikiso Kenkyusho Ltd. (Okayama, Japan). Cepharanthine and its related derivatives were donated by Kaken Pharmaceutical Co. Ltd. (Tokyo, Japan). The drugs tested were dissolved in ethanol, the amount of ethanol added being less than $0.5 \%$ of the final concentration.

Preparation of PMN. PMNs were obtained from the peritoneal cavities of a guinea pigs weighing $300-400 \mathrm{~g}$. The peritoneal fluid was collected $16 \mathrm{~h}$ after an injection of $30-40 \mathrm{ml}$ of $2 \%$ neutrose dissolved in physiological saline solution. It then was washed twice with $\mathrm{Ca}^{2+}$-free Krebs-Ringer-Phosphate (KRP) solution by centrifugation at $500 \times \mathrm{g}$ for $2 \mathrm{~min}$ at room temperature.

Measurement of membrane potential. Membrane potential was measured by the method of Hoffman et al. $(5,22)$ in a fluorospectrophotometer (Shimadzu RF-510). Changes in the fluorescence intensity of the cyanine dye were monitored at $670 \mathrm{~nm}$ after the dye has been excited at $622 \mathrm{~nm}$. The final concentration of cyanine dye was $2.5 \times 10^{-6} \mathrm{M}$. The temperature of the incubation mixture was maintained at $37^{\circ} \mathrm{C}$ and the suspension maintained by magnetic stirring.

Membrane permeability. Release of potassium ion from the cells was measured at $37^{\circ} \mathrm{C}$ with a potassium ion electrode in medium containing $0.15 \mathrm{M}$ choline chloride- $10 \mathrm{mM}$ Tris- $\mathrm{HCl}$ buffer ( $\mathrm{pH}$ 7.4).

Oxygen consumption. Oxygen consumption was measured at $37^{\circ} \mathrm{C}$ with a Clark-type oxygen electrorode in a semiclosed cuvette.

Superoxide generation. Superoxide generation was monitored continuously as the superoxide dismutase-inhibitable cytochrome $\mathrm{c}$ reduction using the method of Nakagawara et al. (13). The incubation mixture was $\mathrm{KRP}$ solution containing $1 \mathrm{mM} \mathrm{CaCl} 20.1 \mathrm{mM}$ $\mathrm{NaN}_{3}, 10 \mu \mathrm{M}$ of cytochrome c, $10 \mathrm{mM}$ glucose and $10^{6}$ cells $/ \mathrm{ml}$ of PMN. The change in absorbance at $550-540 \mathrm{~nm}$ was monitored by a dualbeam spectrophotometer (ShimadzuUV 300).

\section{RESULTS AND DISCUSSION}

Membrane potential changes in PMNs induced by various stimuli. As reported previously $(15,22)$, concanavalin A (Con A) and glucose induce changes in the fluorescence intensity of PMN and Ehrlich ascites tumor cells that had been equilibrated with cyanine dye. Detailed analyses of these changes in fluorescence intensity were made by Seligman and Gallin (18). The addition of formylmethyonyl-leucyl- 


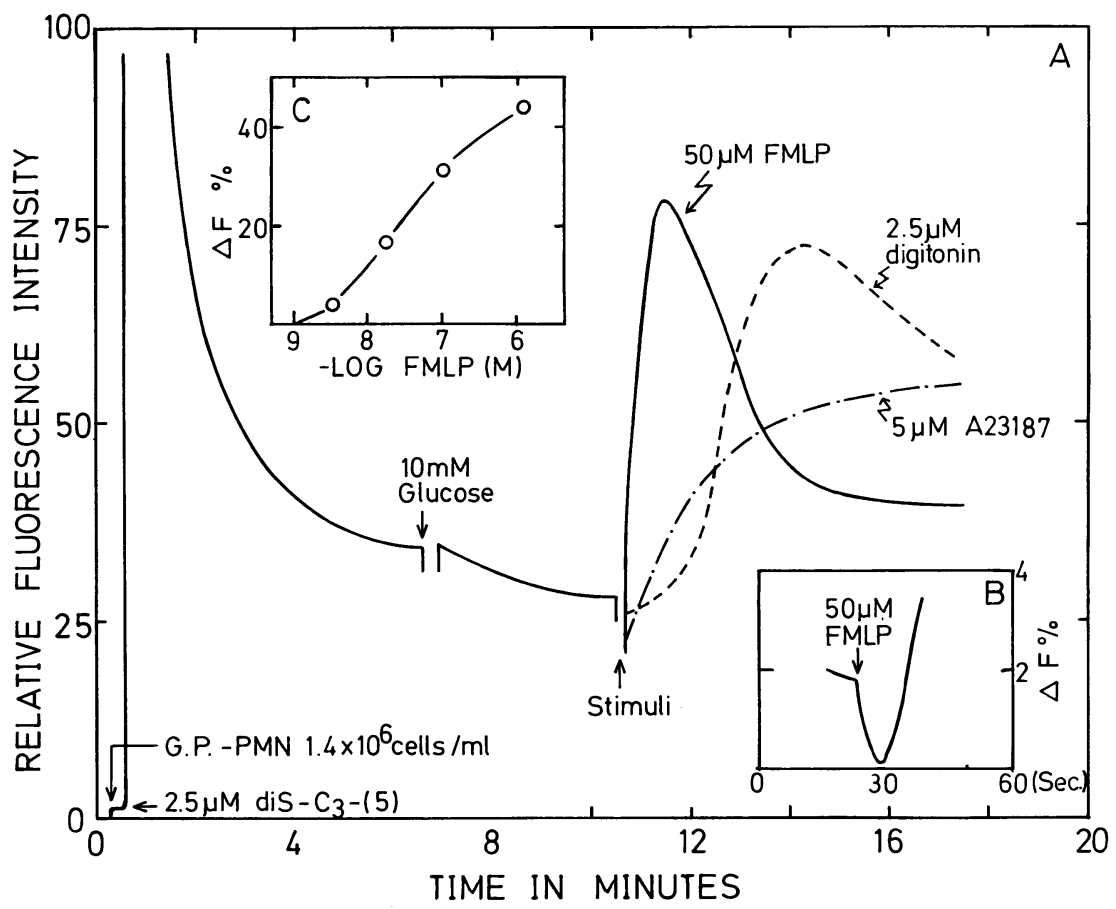

Fig. 1. Changes in the fluorescence of $\mathrm{diS}_{-} \mathrm{C}_{3}-(5)$ in a PMN suspension on the addition of various stimuli. A: Guinea pig PMNs $\left(1.4 \times 10^{6}\right.$ cells $\left./ \mathrm{ml}\right)$ were suspended in KRP solution containing $1 \mathrm{mM}$ $\mathrm{CaCl}_{2}$ and $2.5 \mu \mathrm{M}$ diS- $\mathrm{C}_{3}-(5)$ at $37^{\circ} \mathrm{C}$. Downward deflections in the trace indicate the uptake of cyanine dye by the cells. B: Transitional changes in fluorescence intensity produced by $50 \mu \mathrm{M}$ FMLP (the decrease in fluorescence intensity indicates hyperpolarization). C: Rate of fluorescence change as a function of different concentrations of FMLP.

phenylalanine (FMLP) to PMN produced a biphasic response (Figs. 1A and B). The first phase of that response was a fluorescence decrease (hyperpolarization) and the second a fluorescence increase (depolarization). Similar changes in the fluorescence of PMNs were found after treatment with various types of stimuli; Con $\mathrm{A}, \mathrm{Ca}^{2+}$ ionophore A23187, digitonin and fatty acids. Most of the fluorescence changes produced by these stimuli were transitional, and both the rate and velocity of the changes were stimuli specific and concentration dependent (Fig. 1C).

Relation between membrane potential change and $K^{+}$extrusion. The relation between $\mathrm{K}^{+}$release from PMNs and the fluorescence change in diS- $\mathrm{C}_{3}-(5)$ following the addition of different stimuli to the medium is shown in Fig. 2. Replacement of choline in the medium with $\mathrm{Na}^{+}$slightly decreased the time required to reach the steady-state diS- $\mathrm{C}_{3}-(5)$ uptake, but did not modify the amount of cation accumulated. Conversely, replacement of $\mathrm{Na}^{+}$with $\mathrm{K}^{+}$depressed the steady-state uptake of diS$\mathrm{C}_{3}-(5)$, an indication that the resting potential depends entirely on the $\mathrm{K}^{+}$gradient across the membrane. When PMNs were exposed to FMLP, an immediate release of $\mathrm{K}^{+}$from the cells was detected that was concomitant with a transitional increase in fluorescence intensity. But when exposed to digitonin, after an initial lag period of more than $10 \mathrm{sec}$, a large amount of intracellular $\mathrm{K}^{+}$was released and there was 


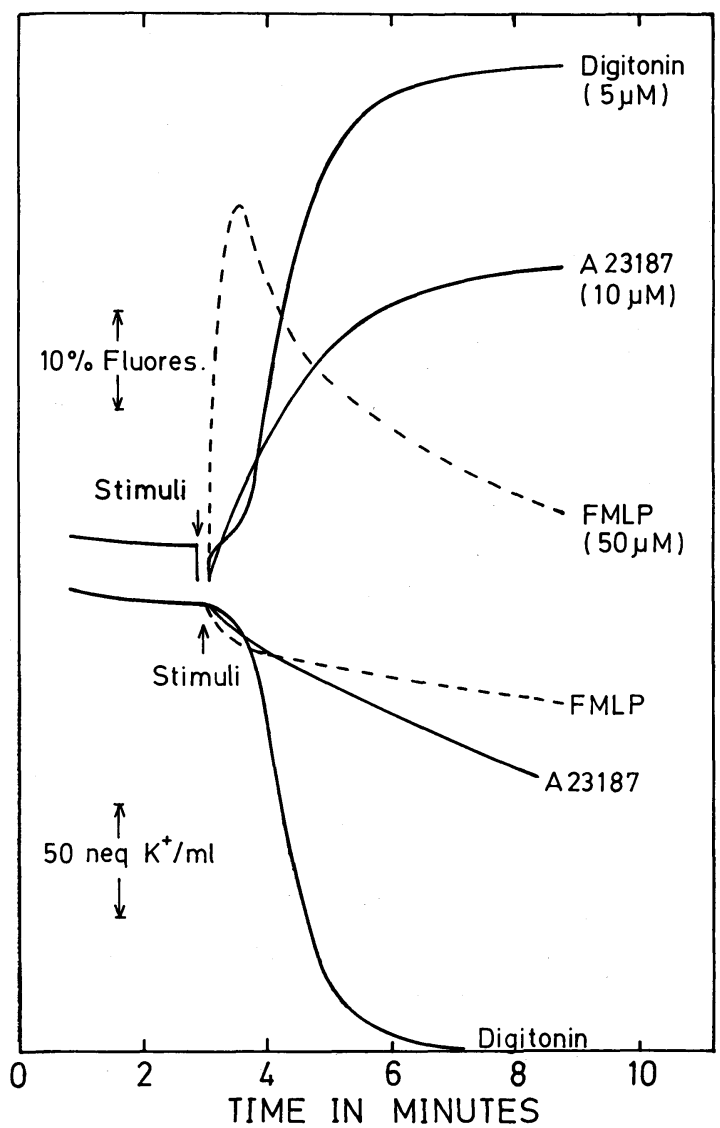

Fig. 2. Relation between $\mathrm{K}^{+}$release from PMNs and the fluorescence change of diS- $\mathrm{C}_{3}-(5)$ on the addition of various stimuli. PMNs $\left(2 \times 10^{6} \mathrm{cells} / \mathrm{ml}\right)$ were incubated in medium containing $0.15 \mathrm{M}$ choline chloride, $10 \mathrm{mM}$ Tris- $\mathrm{HCl}(\mathrm{pH} 7.4), 1 \mathrm{mM} \mathrm{CaCl}_{2}$ and $10 \mathrm{mM}$ glucose at $37^{\circ} \mathrm{C} . \mathrm{K}^{+}$release was monitored with a $\mathrm{K}^{+}$electrode. Other conditions were the same as described in Fig. 1.

a remarkable increase in fluorescence intensity. The initial decrease in fluorescence is consistent with membrane hyperpolarization produced by increased potassium permeability and the later increase in fluorescence is consistent with membrane depolarization caused by a decrease in the $\mathrm{K}^{+}$gradient or in $\mathrm{K}^{+}$permeability.

Calcium ionophore, A23187 also stimulated $\mathrm{K}^{+}$release and the fluorescence change that accompanied superoxide generation. The potency of the ionophore to release intracellular $\mathrm{K}^{+}$was greater than that of FMLP.

Recently, Mottola and Romeo (11) suggested that a stimulus increases the displacement of $\mathrm{Ca}^{2+}$ from the surface membrane of PMNs, and that is partially responsible for the increased permeability of the membrane to other ions, thus inducing a change in the transmembrane diffusion potential. From their evidence it is clear that the stimulus-dependent membrane potential change is closely correlated with the ion permeability of the plasma membrane.

Inhibitory effect of membrane modulators on changes in membrane potential induced by FMLP and digitonin. Recent research on stimulation mechanism has produced 
much information about the series of molecular events that take place on the plasma membrane following its interaction with stimuli. The physical state of phospholipids determines their susceptibility to various enzyme activities in the membrane. Thus interaction of the cell membrane with stimuli could be affected by drugs that interact with the lipids or by various modulators of the physical state of the biological membrane (23).

We used specific inhibitors of phospholipase $A_{2}$ that belong to a group of drugs known as modulators of the physical state of the membrane; mepacrine (21), chlorpromazine (CPZ) (12) and cepharanthine (24). Mepacrine $\left(10^{-4} \mathrm{M}\right)$ totally supressed the depolarization of the cell membrane induced by FMLP (Fig. 3A). The degree of supression was concentration dependent (Fig. 3B) and the half-maximum inhibition was at $20 \mu \mathrm{M}$ mepacrine. FMLP-dependent $\mathrm{K}^{+}$release also was inhibited by the same concentration of mepacrine (data not shown). Similar inhibitory actions were found with cepharanthine (24) and CPZ (16) (Fig. 4), the respective concentrations for half-maximum inhibition being $100 \mu \mathrm{M}$ and $20 \mu \mathrm{M}$. Many of the biscolaurine alkaloid derivatives of cepharanthine, berbamine, tetrandrine, isotrilobine and isotetrandorine showed inhibitory actions similar to the action of cepharanthine. With high concentrations of these membrane modulators, the release of $\mathrm{K}^{+}$from neutrophils also was induced (data not shown).

Our results show that the drugs tested in these experiments caused modification of the cell membrane and that the permeability of small ions across the plasma membrane was greatly modulated. In contrast, digitonin-induced membrane-depolarization (Fig. 5) and $\mathrm{K}^{+}$-release were enhanced by these drugs in a concentration-

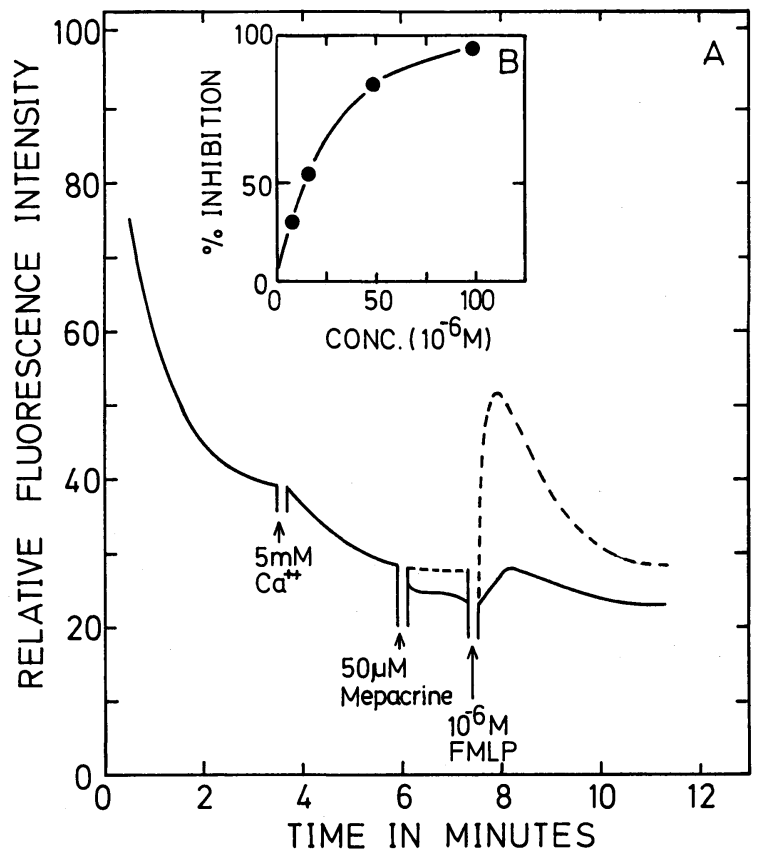

Fig. 3. Effect of mepacrine on the fluorescence change of diS- $\mathrm{C}_{3}-(5)$ in PMN induced by FMLP. A: Experimental conditions were the same as described in Fig. 1 except that $5 \mathrm{mM} \mathrm{CaCl}_{2}$ was present. B: $\%$ inhibition of fluorescence change as a function of different concentration of mepacrine. 


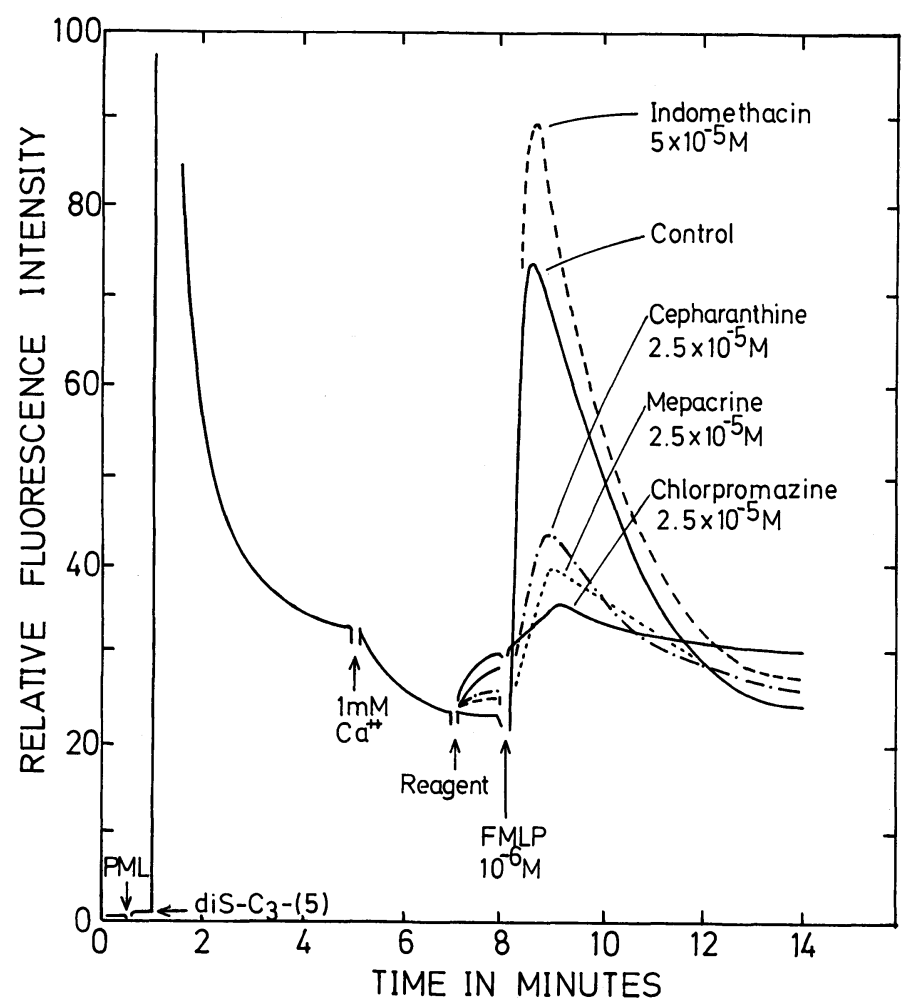

Fig. 4. Effects of various membrane modulators on the fluorescence change of the diS-C $\mathrm{C}_{3}-(5)$ of PMN induced by FMLP. Experimental conditions were the same as described in Fig. 3.

dependent manner. No effects of the drugs were observed on depolarization with the calcium ionophore, A23187 (data not shown). Indomethacin, an inhibitor of cycloxigenase, had no effect on the stimuli-induced membrane depolarization (Fig. 4). The exact mechanism of the differential effect of these drugs on the membrane potential change induced by FMLP or digitonin is still not clear; probably the different responses of potential change to modulators is correlated with changes in membrane permeability.

Inhibitory effects of membrane modulators on the superoxide generation of PMN. The effects of membrane modulators on superoxide generation of PMN, induced by treatment with FMLP or digitonin, are shown in Figs. 6 and 7. The oxygen burst was concomitant with superoxide generation. The rate of superoxide generation was 30 nmoles $\mathrm{O}_{2} / \mathrm{min} / 10^{7}$ cells when stimulated with $5 \times 10^{-8} \mathrm{M}$ FMLP. Similar superoxide generation was induced with $5 \times 10^{-6} \mathrm{M}$ digitonin. Mepacrine and cepharantine inhibited the stimulus-dependent superoxide generation and the oxygen burst as does CPZ (12): Mepacrine or CPZ incubated for $3 \mathrm{~min}$ before stimulation with FMLP or digitonin inhibited superoxide generation of PMNs in a cooperative manner (the hill coefficients for mepacrine and CPZ were 1.68 and 1.92 in FMLP stimulation, and 1.12 and 1.42 in digitonin stimulation). Concentrations for half-maximum inhibition were $20 \mu \mathrm{M}$ mepacrine and $10 \mu \mathrm{M} \mathrm{CPZ}$ for FMLP, and $18 \mu \mathrm{M}$ mepacrine and $5 \mu \mathrm{M} \mathrm{CPZ}$ for digitonin. Thus, in cells in which 


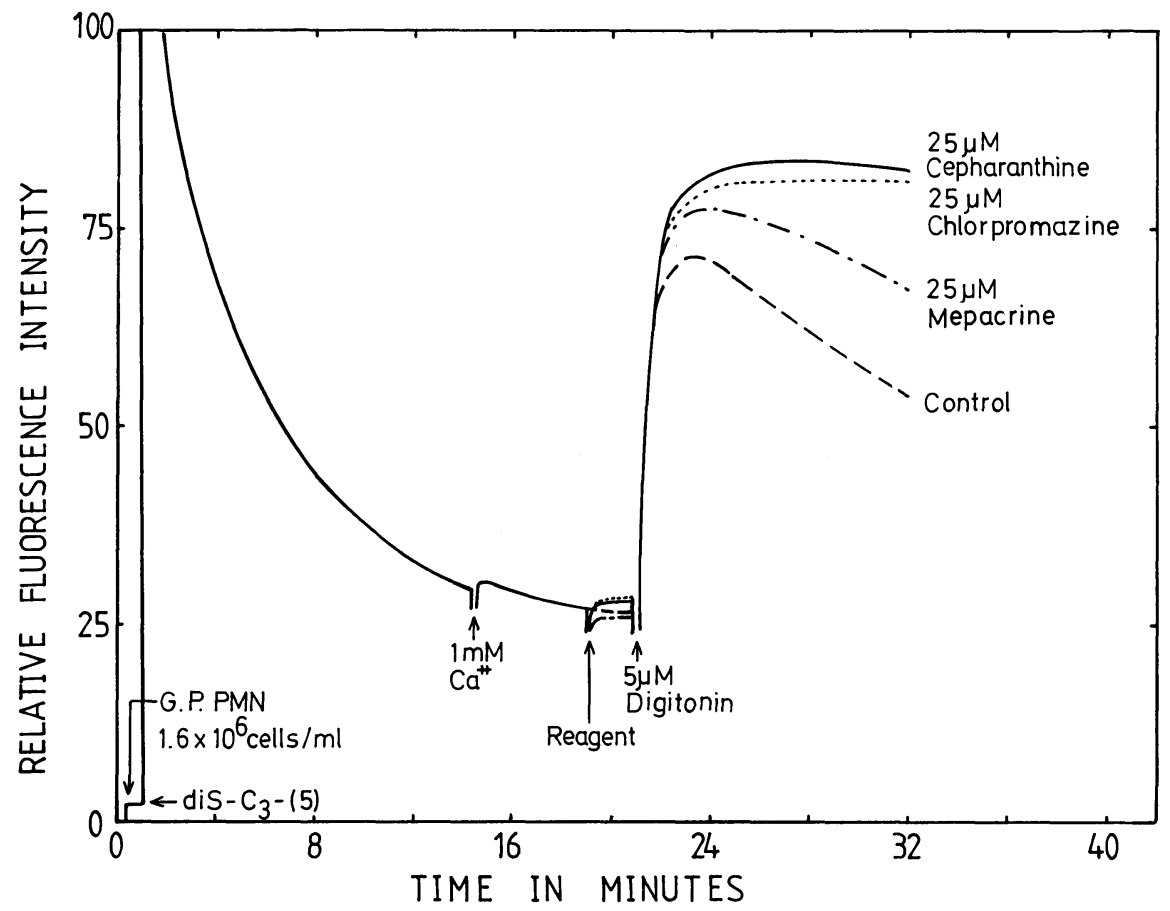

Fig. 5. Effects of various membrane modulators on the fluorescence change of the diS- $\mathrm{C}_{3}-(5)$ of PMN induced by digitonin. Experimental conditions were the same as described in Fig. 4 except that the stimulus was $5 \mu \mathrm{M}$ digitonin.

depolarization could be demonstrated, it was linked neither to changes in superoxide generation nor to respiratory bursts. These results agree with the findings of several investigators who used in different systems $(2,8,9,11,17,21)$.

Recently a $\mathrm{Ca}^{2+}$-activated and phospholipid-dependent protein kinase (protein kinase C) has been shown to function in the activation of several responses in various types of cells (14). Many drugs, including the membrane modulators CPZ and cepharanthine, inhibit the activity of this enzyme, presumably by affecting its interaction with phospholipid (12). This evidence together with our results suggest that protein kinase $\mathrm{C}$ could be correlated with superoxide generation through unidentified intermediate activation steps between ligand binding and NADPH-oxidase expression, but not with stimulus-dependent depolarization and $\mathrm{K}^{+}$-release.

Our results also indicate that common and different steps are involved in the transport of different signals as well as for different responses.

Acknowledgment. We thank Miss Yuki Ohara for preparing the manuscript.

\section{REFERENCES}

1. Badwey, J.A., T. Curnutte, J.M. Robinson, C.B. Berd, M.J. Karnowsky and M.L. KARNOVSKY. Effects of free fatty acids on release of superoxide and on change of shape by human neutrophils. Reversibility by albumin. J. Biol. Chem. 259, 7870-7877, 1984

2. Bianca, V.D., P. Bellavite, P.D. Togni, R. Fuimarulo and F. Rossi. Studies on stimulus- 


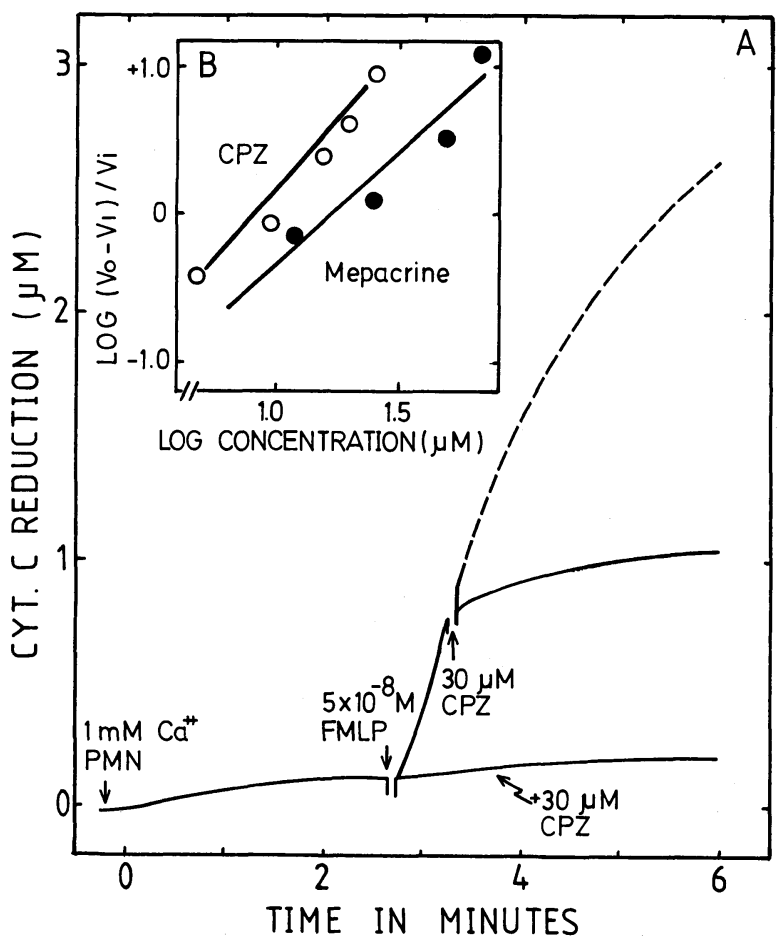

Fig. 6. Effects of mepacrine and $\mathrm{CPZ}$ on superoxide generation by PMN as stimulated by FMLP. A : Superoxide generation was monitored continuously by following the reduction of ferricytochrome $c$ in KRP solution. Medium containing $0.1 \mathrm{mM} \mathrm{NaN}_{3}, 1 \mathrm{mM} \mathrm{CaCl}_{2}, 10 \mathrm{mM}$ glucose and $10 \mu \mathrm{M}$ cytochrome $\mathrm{c}$ as described in MATERIALS AND Methods. CPZ inhibited superoxide generation when added to cells already stimulated. B: Dose responses for the inhibition of superoxide generation were graphed as Hills plots as described elsehwere (15). Cells first were treated with CPZ or mepacrine for $3 \mathrm{~min}$ before stimulation.

response coupling in human neutrophils. 1. Role of monovalent cations in the respiratory and secretory response to N-formylmethionuylleucylphenylanlanine. Biochim. Biophys. Acta 755, 497-505, 1983

3. Costa, T., D. Rodbard and C. Pert. Is the benzodiazepine receptor coupled to a chloride anion channel? Nature 277, 315-317, 1979

4. Duque, R.E., S.H. Phan, M.C. Sulavik and P.A. Ward. Inhibition by tozyl-1-phenylalanyl chloromethyl ketone of membrane potential changes in rat neutrophils. J. Biol. Chem. 258, 8123-8128, 1983

5. Hoffman, J.F. and P.C. LARIS. Determination of membrane potential in human and amphibiuma red blood cells by means of fluorescent probe. J. Physiol. 239, 519-552, 1974

6. Jones, G.S., K. VANDyke and V. Castranova. Transmembrane potential changes associated with superodxide release from human granulocytes. J. Cell. Physiol. 106, 75-83, 1981

7. Kuroki, M., H. Satoh, N. Kamo and Y. Kobatake. Contribution to the membrane potential of the electrogenic $\mathrm{Na}^{+}, \mathrm{K}^{+}$-pump in guinea pig polymorphonuclear leukocytes. FEBS Lett. 123, 177-181, 1981

8. Kuroki, M., N. Kamo, Y. Kobatake, E. Okimasu and K. Utsumi. Measurement of membrane potential in polymorphonuclear leukocytes and its changes during surface stimulation. Biochim. Biophys. Acta 693, 326-334, 1982 


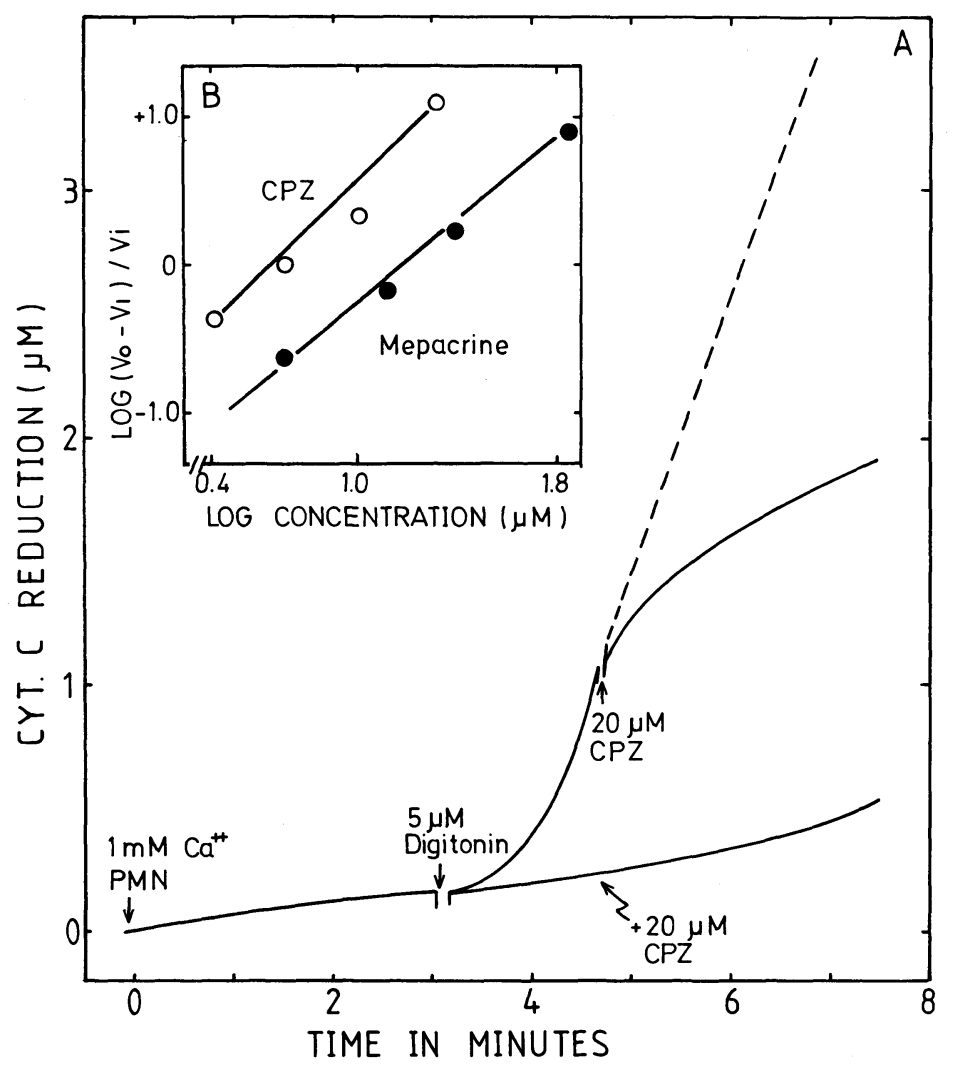

Fig. 7. Effect of mepacrine and $\mathrm{CPZ}$ on superoxide generation by digitonin. Experimental conditions were the same as described in Fig. 6.

9. Lepoivre, M., J. Yenu and J. Petit. Transmembrane potential variations accompanying the PMN-triggered $\mathrm{O}_{2}^{-}$and $\mathrm{H}_{2} \mathrm{O}_{2}$ release by mouse peritoneal macrophages. FEBS Lett. 149, 233-239, 1982

10. Miles, P.R., L. Bowmian and V. Castranova. Transmembrane potential changes during phagocytosis in rat alveolar macrophages. J. Cell Physiol. 106, 109-117, 1981

11. Motrola, C. and M. Romeo. Calcium movement and membrane potential change in early phase of neutrophil activation by phorbol myristate acetate: A study with ion-selective electrodes. J. Cell Biol. 93, 129-134, 1982

12. Mori, T., Y. Takai, R. Minakuchi, B. Yu and Y. Nishizuka. Inhibitory action of chlorpromazine, dibucain, and other phospholipid-interacting drugs on calcium-activated, phospholipid-dependent protein kinase. J. Biol. Chem. 255, 8379-8380, 1980

13. Nakagawara, A., K. Shibata, K. Takeshige and S. Minakami. Action of cytochalasin E on polymorphonuclear leukocytes of guinea pig peritoneal exudates. Exp. Cell Res. 101, 225234, 1976

14. Nishizuka, Y. Turnover of inositol phospholipid and signal transduction. Science 225, 13651370, 1984

15. Okimasu, E., J. Akiyama, N. Shiraishi and K. Utsumi. The mechanism of inhibition on endogenous respiration of Ehrlich ascites tumor cells by a cyanine dye, diS-C ${ }_{3}-(5)$. Physiol. Chem. Phys. 11, 425-433, 1979

16. Robinson, J.M., J.A. BADWEy, M.L. KaRnovsky and M.J. KaRnovsKy. Release of superoxide 
and change in morphology by neutrophils in response to phorbol esters: Antagonism by inhibitors of calcium-binding proteins. J. Cell Biol. 101, 1052-1058, 1985

17. Rossi, F., V.D. BlanCA and A. DAvoli. A new way for inducing a respiratory burst in guinea pig neutrophils. Changes in $\mathrm{Na}^{+}, \mathrm{K}^{+}$concentration of the medium. FEBS Lett. 1332, 273277,1981

18. Seligmann, B.E. and J.I. Gallin. Secretagogue modulation of the response of human neutrophils to chemoattractants: Studies with a membrane potential sensitive cyanine dye. Mol. Immunol. 17, 191-200, 1980

19. Seligmann, B.E., E.K. Gallin, D.L. Martin, W. Shain and J.I. Gallin. Interaction of chemotactic factors with human polymorphonuclear leukocytes: Studies using a membrane potential-sensitive cyanine dye. J. Membrane Biol. 52, 257-272, 1980

20. Schiffman, E. and J.T. Gallin. Biochemistry of phagocyte chemotaxis. Current Topics in Cell Regulation 15, 203-261, 1979

21. TAUBER, A.I. and E.R. SimONS. Dissociation of human neutrophil membrane depolarization, respiratory burst stimulation and phospholipid metabolism by quinacrine. FEBS Lett. 156, 161-164, 1983

22. Utsumi, K., K. Sugiyama, M. Miyahara, M. Naito, M. Awai and M. Inoue. Effect of concanavaline $\mathrm{A}$ on membrane potential of polymorphonuclear leukocyte monitored by fluorescent dye. Cell Struct. Funct. 32, 203-209, 1977

23. VIGoI, C., G.P. Lewis and R.J. PIPER. Mechanism of inhibition of phospholipase $A_{2}$. Biochem. Pharmacol. 29, 623-627, 1980

24. Watanabe, S., Y. Morimoto, N. Shiraishi and K. Utsumi. The inhibition of platelet aggregation by biscoclaurine alkaloid. Cell Struct. Funct. 6, 263-267, 1981

25. Whitin, J.C., C.E. Chapman, E.R. Simons, M.E. Chovoaniec and H.J. Cohen. Correlation between membrane potential changes and superoxide production in human granulocytes stimulated by phorbol myristate acetate. J. Biol. Chem. 255, 1874-1879, 1980

(Received for publication, March 6 -1986) 